\title{
ASSESSMENT OF THE SHEAR STRENGTH OF POLYOLEFIN AND STEEL FIBRE-REINFORCED CONCRETE
}

\author{
${ }^{1}$ Álvaro Picazo; ${ }^{2}$ Marcos G. Alberti; ${ }^{2}$ Alejandro Enfedaque; ${ }^{2}$ Jaime C. Gálvez \\ ${ }^{1}$ Departamento de Tecnología de la Edificación, E.T.S de Edificación, Universidad \\ Politécnica de Madrid. Av. Juan de Herrera, 6, 28040, Madrid. \\ ${ }^{2}$ Departamento de Ingeniería Civil: Construcción, E.T.S de Ingenieros de Caminos, \\ Canales y Puertos, Universidad Politécnica de Madrid. C/ Profesor Aranguren, s/n, \\ 28040, Madrid.
}

Keywords: Fibre-reinforced concrete, shear strength, uniaxial tests, digital image correlation.

Fibre reinforced concrete (FRC) is a composite material that has been used in the last 50 years for structural applications such as industrial floors, slabs, precast elements or tunnel segments [1]. The addition of randomly distributed fibres improves the flexural and tensile response of the material. Moreover, if certain requirements of the standards are met, the contributions of the fibres can be considered in the structural design. That is to say, fibres can replace, total or partially, the conventional steel re-bars. Recent applications have shown that FRC is an attractive solution for structural elements [2, 3].

Among the wide range of fibres available, steel and polyolefin ones are those considered as structural fibres in the existing standards. The structural requirements for considering the contribution of the fibres in the structural design are established in similar terms in the Spanish structural concrete code EHE08 [4] and the Model Code

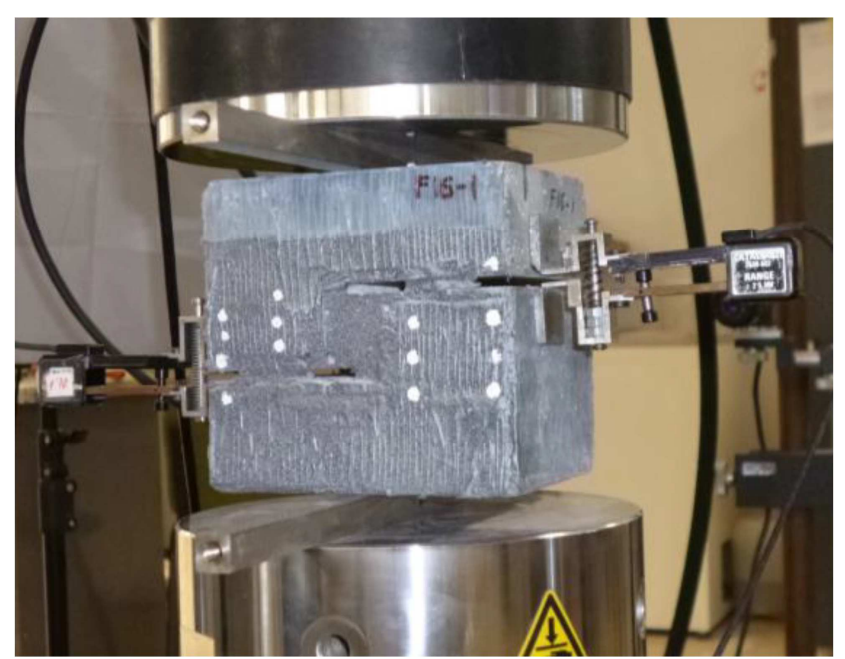

Fig. 2. Push-off test setup

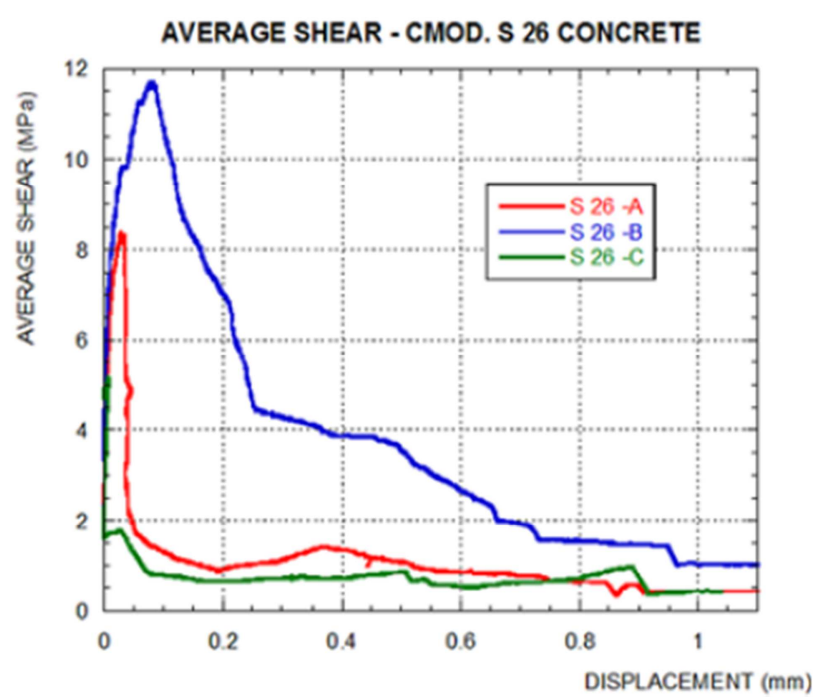

Fig. 1. Shear-displacement curve of three specimens of SFRC with $26 \mathrm{Kg} / \mathrm{m}^{3}$ of steel hooked fibres. 2010 [5]. Such standards 
require certain values of residual strengths in three-point bending tests with notched specimens, following the test described in EN-14651. Given that such requirements are defined as certain values of flexural tensile residual strength, flexural behaviour of FRC has been extensively studied [6].

However, structural design involves considering shear contributions of the fibres and there is a lack of research about shear behaviour of steel fibre reinforced concrete (SFRC), especially without re-bars. Moreover, in the case of polyolefin fibre-reinforced concrete (PFRC) it is still a matter of research.

The aim of this study was to assess the shear behaviour of both SFRC and PFRC. In order to do so, an experimental campaign using double notched specimens was carried out. Push-off tests as the one shown in Figure 1 were performed. The tests were designed with two lateral crack mouth opening displacement gauges. Additionally, digital image correlation (DIC) was synchronised to associate the cracking processes taking place during the test with shear stresses.

SFRC specimens with steel hooked fibres and dosages of 26 and $70 \mathrm{Kg} / \mathrm{m}^{3}$ were tested. In the case of PFRC, the specimens were reinforced with $10 \mathrm{Kg} / \mathrm{m}^{3}$ of $60 \mathrm{~mm}$ long polyolefin fibres.

The results showed how higher contents of fibres improved the maximum shear strength as well as the values of residual shear strengths. DIC analysis allowed the correlation of cracking processes and identifying the loads at which the initial cracks appear. This can be seen in Figure 2 and Figure 3.

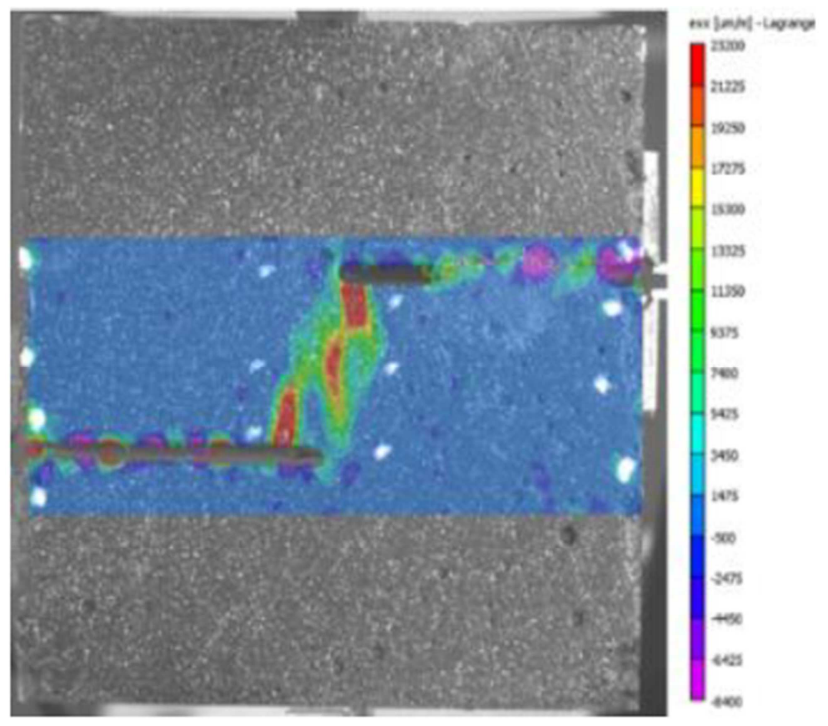

Fig. 3. Cracked specimen analysed by DIC

\section{REFERENCES}

[1] P. Serna, S. Arango, T. Ribeiro, a. M. Núñez and E. Garcia-Taengua, "Structural cast-in-place SFRC: technology, control criteria and recent applications in spain.," Materials and Structures, 42(9), p. 1233-1246, 2009.Albert Sánchez Rodríguez, Análisis de la aplicabilidad de los áridos reciclados mixtos en hormigones-2011, 31-52.

[2] K. Behfarnia and A. Behravan, "Application of high performance polypropylene fibers in concrete lining of water tunnels," Materials \& Design, vol. 55, pp. 274-279, 2014.Belén González Fonteboa, Diagrama tensión-deformación del hormigón con árido reciclado no saturado-2009, 1-9. 
[3] M. Di Prisco, M. Colombo and D. Dozio, "Fibre-reinforced concrete in fib Model Code 2010: principles, models and test validation," Structural Concrete, vol. 14(4), pp. 342-361, 2013.

[4] EHE-08, Spanish Structural Concrete Code, Spanish Minister of Public Works, 2008.

[5] fib Model Code, Model Code, Paris: Fédération Internationale du Béton fib/International Federation for Structural Concrete, 2010.

[6] M. G. Alberti, A. Enfedaque and J. C. Gálvez, "On the mechanical properties and fracture behavior of polyolefin fiber-reinforced self-compacting concrete," Construction and Building Materials, vol. Volume 55, pp. 274-288, 2014. 